OPEN ACCESS

Edited by:

Hans Ulrich Häring,

Tübingen University

Hospital, Germany

Reviewed by:

Alessandro Cavarape,

University of Udine, Italy

Andreas Peter,

Tübingen University

Hospital, Germany

*Correspondence:

Natália Cruz-Martins

ncmartins@med.up.pt

Gaber El-Saber Batiha

gaberbatiha@gmail.com

${ }^{\dagger}$ These authors have contributed equally to this work

Specialty section

This article was submitted to

Clinical Diabetes,

a section of the journal

Frontiers in Public Health

Received: 11 September 2020 Accepted: 29 April 2021

Published: 07 July 2021

Citation:

Magdy Beshbishy A, Oti VB, Hussein DE, Rehan IF, Adeyemi OS, Rivero-Perez N, Zaragoza-Bastida A, Shah MA, Abouelezz K, Hetta HF Cruz-Martins N and Batiha GE-S

(2021) Factors Behind the Higher COVID-19 Risk in Diabetes: A Critical

Review.

Front. Public Health 9:591982 doi: 10.3389/fpubh.2021.591982

\section{Factors Behind the Higher COVID-19 Risk in Diabetes: A Critical Review}

\author{
Amany Magdy Beshbishy ${ }^{1 t}$, Victor B. Oti ${ }^{2}$, Diaa E. Hussein ${ }^{3}$, Ibrahim F. Rehan ${ }^{4}$, \\ Oluyomi S. Adeyemi ${ }^{5}$, Nallely Rivero-Perez ${ }^{6}$, Adrian Zaragoza-Bastida ${ }^{6}$, \\ Muhammad Ajmal Shah ${ }^{7}$, Khaled Abouelezz ${ }^{8}$, Helal F. Hetta ${ }^{8}$, Natália Cruz-Martins ${ }^{9,10,11 *}$ \\ and Gaber El-Saber Batiha ${ }^{12 * t}$
}

\begin{abstract}
${ }^{1}$ National Research Center for Protozoan Diseases, Obihiro University of Agriculture and Veterinary Medicine, Obihiro, Japan, 2 Department of Microbiology, Nasarawa State University, Keffi, Nigeria, ${ }^{3}$ Researcher, Department of Food Hygiene, Agricultural Research Center, Animal Health Research Institute, Port of Alexandria, Egypt, ${ }^{4}$ Department of Husbandry and Development of Animal Wealth, Faculty of Veterinary Medicine, Menofa University, Shebin Alkom, Egypt, ${ }^{5}$ Medicinal Biochemistry, Infectious Diseases, Nanomedicine \& Toxicology Laboratory, Department of Biochemistry, Landmark University, Omu-Aran, Nigeria, ${ }^{6}$ Área Académica de Medicina Veterinaria y Zootecnia, Instituto de Ciencias Agropecuaria, Universidad Autónoma del Estado de Hidalgo, Tulancingo, Mexico, ' Department of Pharmacognosy, Faculty of Pharmaceutical Sciences, Government College University, Faisalabad, Pakistan, ${ }^{8}$ Department of Medical Microbiology and Immunology, Faculty of Medicine, Assiut University, Assiut, Egypt, ${ }^{9}$ Faculty of Medicine, University of Porto, Porto, Portugal, ${ }^{10}$ Institute for Research and Innovation in Health (i3S), University of Porto, Porto, Portugal, " Laboratory of Neuropsychophysiology, Faculty of Psychology and Education Sciences, University of Porto, Porto, Portugal, ${ }^{12}$ Department of Pharmacology and Therapeutics, Faculty of Veterinary Medicine, Damanhour University, Damanhour, Egypt
\end{abstract}

Diabetes mellitus (DM) and coronavirus disease 2019 (COVID-19) are public health issues worldwide, and their comorbidities trigger the progress to severe disease and even death in such patients. Globally, DM has affected an estimated 9.3\% adults, and as of April 18, 2021, the World Health Organization (WHO) has confirmed 141,727,940 COVID-19 confirmed cases. The virus is spread via droplets, aerosols, and direct touch with others. Numerous predictive factors have been linked to COVID-19 severity, including impaired immune response and increased inflammatory response, among others. Angiotensin receptor blockers and angiotensin converting enzyme 2 have also been identified as playing a boosting role in both susceptibility and severity to severe acute respiratory syndrome coronavirus 2 (SARS-CoV-2). Specifically, in DM patients, both their control and management during this pandemic is herculean as the restriction periods have markedly hampered the maintenance of means to control glycemia, hypertension, and neuroendocrine and kidney diseases. In addition, as a result of the underlyin cardio-metabolic and immunological disorders, DM patients are at a higher risk of developing the severe form of COVID-19 despite other comorbidities, such as hypertension, also potentially boosting the development of higher COVID-19 severity. However, even in non-DM patients, SARS-CoV-2 may also cause transient hyperglycemia through induction of insulin resistance and/or pancreatic $\beta$-cell injury. Therefore, a strict glucose monitoring of DM patients with COVID-19 is mandatory to prevent life-threatening complications.

Keywords: diabetes, COVID-19, SARS-CoV-2, comorbidities, mortality 


\section{INTRODUCTION}

\section{COVID-19 Disease: An Overview}

Coronavirus disease 2019, named COVID-19, discovered in Wuhan, China, is being quickly transmitted to the worldwide population. The viral agent, known as severe acute respiratory syndrome coronavirus 2 (SARS-CoV-2) is capable of inducing severe to acute pneumonia, lethal lung failure, and even death in susceptible hosts (1). Genetically, this virus differs from the closely related SARS members and is classified into the group of beta coronavirus infecting humans (2). Despite having a negative impact on the respiratory tract, clinical features range from asymptomatic to moderate-to-serious or critical disease. Currently, the viral infection case fatality rate is $<5 \%$, but $15-18 \%$ of infected patients may develop the severe form of the disease, even becoming critically ill, and others may need mechanical ventilation and intensive care unit (ICU) admission (3).

Declared a worldwide pandemic on March 11, 2020, by the World Health Organization (WHO) (4), the SARS-CoV2 infection triggers various clinical manifestations, including respiratory tract disorders, severe pneumonia, septic shock, and multiorgan failure (4). However, clinical data available so far reveal that children aged $<10$ years usually remain asymptomatic and has a low case fatality rate (5). The median incubation period is 4 days, ranging from 2 to 14 days maximum $(5,6)$. The viral agent is shown to be spread via droplets, aerosols, and through direct contact with infected individuals. Concerning the virus dissemination via droplets, it can happen if a respiratory droplet is generated when an infected individual sneezes or coughs, and it is ingested or inhaled by close people (about 6 feet away). Thus, an individual may become infected by mere touching of surfaces or objects that harbor the viral agent and subsequently touching the nose, mouth, or eyes (7). Increased viral loads have been reported as soon as the symptoms start to appear, which suggests that viral transmission is more likely to occur early in viral infection (8). The duration of viral shedding differs based on the disease severity. For instance, Liu et al. (9) report that mild symptoms were found in 90\% of COVID-19 patients who show a negative virus RNA test with swabs from the nasopharyngeal region by day 10 post-onset. Meanwhile, for a long time, the test remained positive in all severe cases. A study by Zou et al. (8) found that the detected viral load in patients without symptoms was similar to those that show symptoms. Indeed, there is evidence of spread of the viral agent during the incubation period of patients without symptoms (10).

\section{Diabetes: An Overview}

Diabetes mellitus (DM) is among the world's greatest causes of morbidity with a high anticipation of exponential increase in the coming decades (11). The condition has several macro and microvascular complications as its predictors, which negatively affect the patient's overall survival (12). Globally, DM has affected about $9.3 \%$ of adults, there is a likelihood of it skyrocketing to $10.2 \%$ by the year 2030 , and it might reach $10.9 \%$ by the year 2045 (13). In the last three decades, China has seen DM rise 17 -fold, giving it the controversial slogan the "Diabetes
World Capital" (14). Several metabolic predictors have been listed as triggers for metabolic disorders (DM and obesity, inclusive), such as chronic inflammation, oxidative stress, subclinical atherosclerosis, endothelial dysfunction, insulin resistance, glucose metabolism, and changed lipid, among others (14).

\section{DIABETES AND INFECTIOUS DISEASES}

The interlink between DM and infectious diseases has been underlined by several clinical studies $(15,16)$. DM patients are more prone to infections as compared with those without DM as a result of impaired immunity $(16,17)$. Scientific evidence has found a greater rate of susceptibility to infectious diseases in DM individuals (Figure 1), such as those triggered by Mycobacterium tuberculosis and Staphylococcus aureus (18), directly attributed a dysregulated immune system (17). There is a general perception that DM patients can have higher morbidity and death rates by infectious diseases, and there is a paucity of epidemiologic data that would make it evident. There are reports that try to look at DM as a predisposing factor to some infection that can lead to death $(19,20)$. In this way, different viral infections are reported to increase the vulnerability of DM patients (21), such as those deriving from SARS-CoV (19), Middle East respiratory syndrome coronavirus (MERS-CoV) (21), and the 2009 influenza A (H1N1) infection (20). A recent review summarizing the clinical features linked to a higher risk of acquiring infectious diseases among DM individuals underlined that poorly controlled DM is a major risk factor, including for SARS-CoV-2 infection (22).

\section{CORONA VIRUS RECEPTORS}

SARS-CoV-2, similarly to SARS-CoV, uses angiotensin converting enzyme 2 (ACE2) as a cellular receptor (Figure 2),

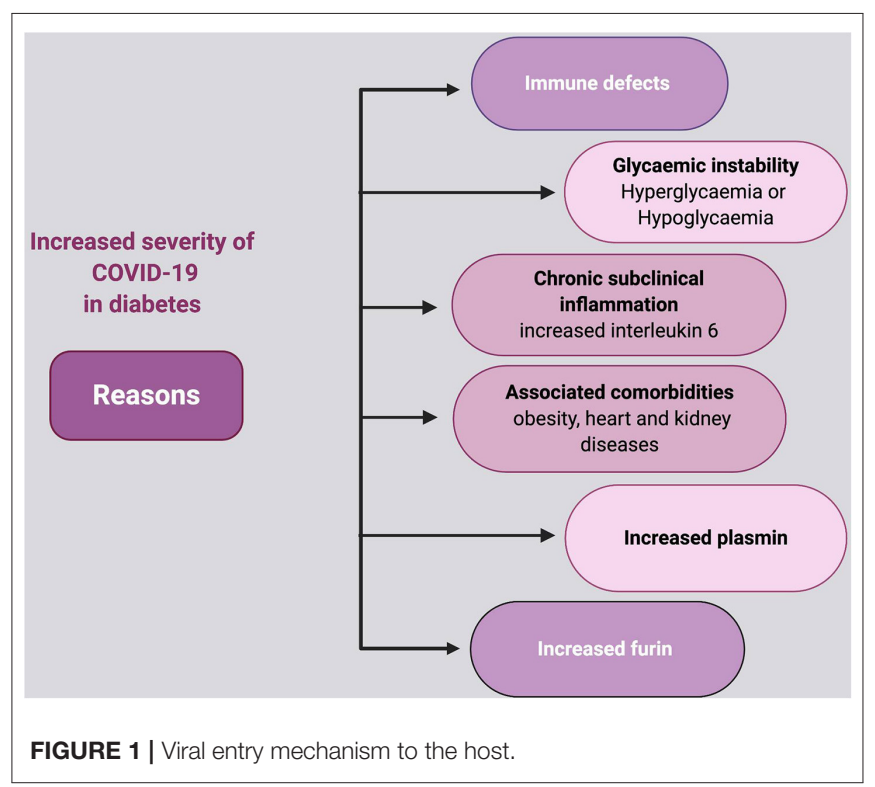




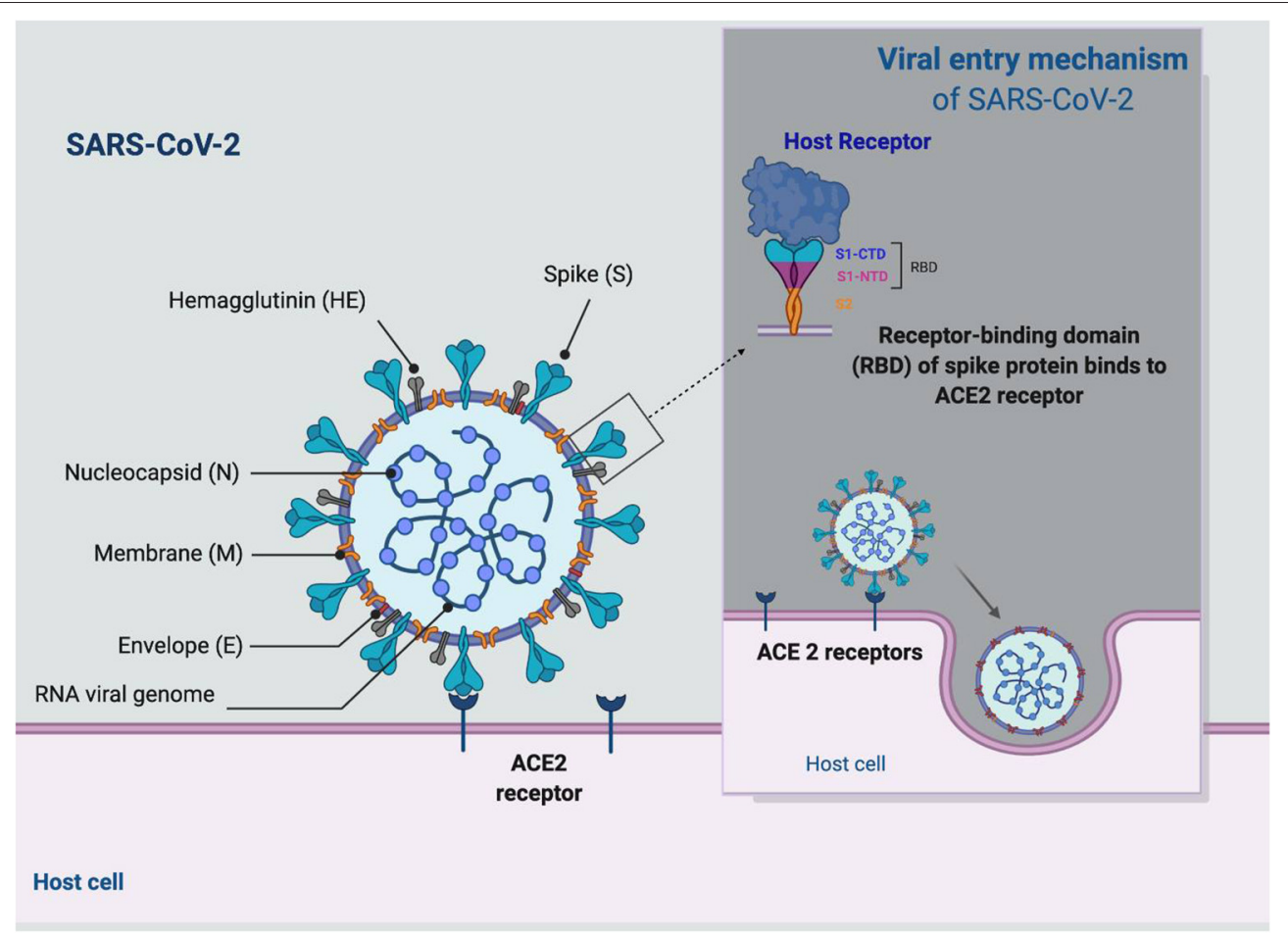

FIGURE 2 | Diabetes as a risk factor for COVID-19.

interacting directly with the spike glycoprotein (23). Wrapp et al. (24) report that the interaction between ACE2 and receptor-binding domain $(\mathrm{RBD})$ is 10 to 20 times higher than the enzyme found in other coronaviruses. The enzyme has been found in myriad organ systems, including the heart, kidneys, brain, and lungs, among others (25). Indeed, there is evidence that the counter-regulatory enzyme ACE2, which metabolizes angiotensin II (Ang II), can enhance SARS-CoV-2 entry and replication (26). Many reports implicate the role of renin-angiotensin system (RAS) activation and reduced ACE2 expression in the process of lung injury following viral infection (27). As such, viral infection and type $2 \mathrm{DM}$ (T2DM) have related pathogenic flow charts that have an implication in the treatment process (27). Additionally, dipeptidyl peptidase 4 (DPP4) and ACE2 regulate cardiovascular (CV) and renal physiology, inflammation, and glucose homeostasis. DPP4 inhibitors are greatly functional in T2DM patients due to their role in reducing glycemia although their role in the immune response of such patients is still not clear or fully established (28). Meta-analyses illustrate that DPP4 inhibitors do not raise the risk of acquiring infections (29-31), a feature that is also confirmed by Yang et al. (32), who did not report a high risk of infections due to pathogens with DPP4 inhibitors.

Indeed, a recent review highlights that deregulation of DPP4 receptors in COVID-19 as well as the upregulation of these receptors may be a determinant in COVID-19 severity. Therefore, the use of DPP4 inhibitors (gliptins) in COVID-19 management should be better exploited to improve the overall knowledge on how DPP4 may be useful to design novel therapies to block SARS-CoV-2 entry (33).

Other receptors on the human cell surface have been reported to facilitate the penetration of the viral agent, including transmembrane serine protease 2 (TMPRSS2) (34), extracellular matrix metalloproteinase inducer (35), and sialic acid receptors (36). Furthermore, cathepsins L and B have been reported to be key penetrating factors in the COVID-19 pathogenesis (34).

\section{DIABETOGENIC VIRUSES}

Data from animal and human studies postulate that there are diabetogenic viral agents, but they are few (37). Two different studies found two DM patients who depend on acute insulin for a short and transient period following chicken pox infection (38). Guo et al. (26) recommend that viral infection could induce fast changes in blood glucose levels of DM patients, playing a negative role in such patients' recovery. Yang et al. (19) report an increase in fasting blood sugar (FBS), even in patients with non-severe SARS, who did not receive glucocorticoid therapy.

Briefly, coronavirus can trigger DM by inducing damage to the islets. This assertion is backed by the strong nature of immunostained ACE2 protein and its weak nature in exocrine tissues (39). Findings obtained so far show that DM and SARS$\mathrm{CoV}-2$ pneumonia can be entangled, and this may be detrimental to the COVID-19 prognosis. 


\section{MORBIDITY OF SARS-COV-2 INFECTION IN DIABETIC PATIENTS}

Yang et al. (19) reveal that DM and plasma glucose levels are independent probable factors for morbimortality in SARS-CoV2 infected patients. In China (Wuhan), a retrospective study showed that out of the 41 SARS-CoV-2 infected individuals, about $32 \%$ presented with other underlying diseases, $20 \%$ of them diabetic $(40,41)$. Research conducted in 8,910 patients with COVID-19 infection revealed that $14.3 \%$ had DM (42). Similarly, in a study performed in China with 1,099 hospitalized patients with novel coronavirus cases, 81 had DM, and about $34.6 \%$ had a serious ailment related to the $41 / 165$ that had hypertension, 10/27 with coronary artery disorder, 67/261 with some coexisting disease, and 106/838 did not have any coexisting disease (43). Tentolouris et al. (44) carried out a study with 30,000 individuals in Greece and found a $6.6 \%$ incidence rate of DM. DM patients presented a higher incidence of comorbidities, including kidney, heart, and lung diseases. In addition, in the United States, CDC found that in 7,162 cases with incomplete data, above $50 \%$ of them were hospitalized, $10.9 \%$ had DM and $148(18.9 \%)$ need admission into the intensive care unit (ICU) (45). The authors also found that the number of patients needing ICU admission did not differ from that with CV disease (20.4\%) although it was higher than that with chronic lung disease (14.3\%) or at an immuno-compromised status (15.5\%). A report in Kuwait states that individuals with DM and obesity are more prone to ICU admission as the COVID-19 pandemic continues (46).

\section{DM: RISK FACTOR FOR COVID-19}

Studies conducted in recent times show that the elderly or individuals with underlying comorbidities, such as $\mathrm{CV}$ disease, $\mathrm{DM}$, and hypertension, are more susceptible to complications and possibly death as a result of COVID-19 (45). DM has also been found to be an important predictor for the severe form of COVID-19 due to respiratory tract infections (47). Also, DM has been reported to be linked to higher mortality following MERS$\mathrm{CoV}$ and SARS-CoV infections by different studies $(21,47)$, and the level of FBS has been considered an independent probable factor for fatality in SARS infected patients (19). Diabetes is a possible predictor of infection, more so in those aged $>60$ years old and in those with poor glycemic control (48). Currently, there are no public findings, but obviously, there is a higher likelihood that DM patients will get SARS-CoV-2 infection (49). Moreover, it is known that DM and obesity are associated with the synthesis and clearance of dysregulated lipids that can trigger lung inflammation and injury $(50,51)$. In DM patients, the risk of pneumonia or lower and upper respiratory tract infections is greater than that of general population (52). Another study found that COVID-19 patients who have DM not only have a greater risk to severe pneumonia, but also spread inflammatory biomarkers excessively (25). However, DM patients might be at greater risk for hospitalization and development of complications due to COVID-19 (53).
Thus, the presence of patients with DM underlying viral infection is associated with two-fold heightened risk of death and also two-fold greater risk of COVID-19 severity (51). The main possible predictors include uncontrolled blood glucose levels before infection with the new coronavirus, shorter contact with DM healthcare experts, and unusual discontinuation of ACE2 inhibitor. The latter aspect mentioned is stated because reports show that the virus connects to cells via ACE2; therefore, these drugs can heighten the ACE2 level with the ability theoretically that there is a higher pickup of the viral agent. However, halting these medications can cause more damage in most cases (49). Indeed, related studies and reports have reported danger in DM individuals for the two new coronavirus infections discovered, SARS starts in 2002 in Asia and the Middle East, affecting more than 8,000 individuals (54) and MERS in 2012, mostly in Saudi Arabia, which affected more than 2,000 individuals (55).

\section{COMORBIDITY OF DIABETES}

DM is a comorbidity usually reported by COVID-19 patients $(56,57)$. Indeed, about $7 \%$ of COVID-19 patients have DM. Zhou et al. (47) state a recovery rate of $14 \%$ for COVID19 patients with DM although a higher rate was stated (31\%) for patients who were non-survivors. In a new published meta-analysis, it is found that DM incidence in ICU patients with viral infection increased twice in comparison with nonICU patients (58). SARS-CoV-2 infection in DM patients can facilitate increased stress conditions with high release of hyperglycemic hormones, including catecholamines and glucocorticoids, ultimately resulting in high blood sugar levels and abnormalities in glucose levels (59). Recently, in the United States, the Centers for Disease Control and Prevention (CDC) reported that the incidence of DM was $10.9 \%$ in 7,162 patients who had all data on their health status on March 28, 2020 (58). Anyway, data published so far underline that DM patients and severe SARS-CoV-2 infection are older and have comorbidities when compared with non-DM patients (60).

\section{MORTALITY RATES OF DM PATIENTS WITH COVID-19}

A recent study revealed that, among 191 Chinese COVID-19 patients hospitalized, $19 \%$ had DM with 54 deaths being recorded (45). The Chinese Center for Disease Control and Prevention (CCDC) registered a case fatality rate (CFR) of $2.3 \%$ in a detailed study with 44,672 COVID-19 patients. However, the rate increased to $10.5 \%$ in those with CV disease, $7.3 \%$ in those with $\mathrm{DM}$, and $6.0 \%$ in those with hypertension (61). A fatality rate of $35 \%$ was also reported for those with DM as compared with $20 \%$ in the general population (62). Indeed, much research has reported that DM patients suffering from comorbidities have higher mortality rates due to complicated hyperglycemia and myocardial infarction because blood glucose plays a distinct role $(63,64)$. In addition, a recent multicenter retrospective study provides clinical evidence that correlate better blood glucose 
control with good clinical outcomes in COVID-19 patients and preexisting T2DM (65).

Regarding viral agent transmission, it occurs at a high efficiency, which impacts not only healthy individuals, but majorly the elderly, with higher complication rates than other pandemics (66). In several countries, these high rates of disease and death are often found in individuals of older ages and in those with comorbidities (67) although it is not certain if there are variations in the severity of infection between men and women with DM and if it differs between DMT1 and T2 (68). However, men are more prone to develop a severe form of COVID-19 due to underlying cardiometabolic risk factors, hormonal changes, ACE2 expression, inflammatory status, and exaggerated immune response (69). Also, Shahid et al. (70) illustrate that older subjects are at higher risk of death by COVID-19.

Additionally, a study shows that individuals who take corticosteroids for no obvious justification are at high risk (63). Thus, these patients are overrepresented in those at a high death risk from the virus: elderly people and those with comorbidities (5). Also worth noting is that it has been suggested that ACE2 can raise both viral infection susceptibility and severity through enzyme upregulation, which explains the overrepresentation of hypertensive patients in COVID-19 death causes (71). Finally, diabetic kidney disease (DKD) is also a leading factor that triggers disease and death in DM patients with estimations reporting that $30-40 \%$ of DM patients may die from DKD.

\section{DIABETES AND IMMUNE RESPONSE}

Several abnormal immune system changes have been seen in DM patients, well-describing the relationship between immune dysfunction and hyperglycemia, involving weakening of the polymorphonuclear and monocytic white blood cell chemotaxis phagocytosis, complementary role and cytokine dysregulation (72). T2DM is generally recognized by a reduced level of chronic inflammatory disorder, triggered by a prolonged immune system imbalance, metabolic syndrome, and obesity (73). DM leads to proinflammatory homeostatic interactions of the immune system that is geared toward T helper 1 (Th1) and T17 cells and a decline in T-cell regulation (Treg) (17). Indeed, immune system dysfunction due to DM or infection has been observed in a variety of immune cells, not only $\mathrm{CD} 4^{+} \mathrm{T}$ cells, but also monocytes and macrophages (17). A recent study reported that the total number of $\mathrm{CD}^{+}$and $\mathrm{CD} 4^{+} \mathrm{T}$ cells lessens drastically and is functionally drained in SARS-CoV-2 infected patients, particularly in geriatric and in those critically ill who need ICU admission (74). Kulcsar et al. (75) found that DM mice had a long-term serious disease phase and postponed healing from MERS-CoV infection due to immune response dysregulation with lower rates of inflammatory $\mathrm{CD}^{+} \mathrm{T}$ cells and monocytes/macrophages. Moreover, several research studies found a greater risk of severe COVID-19 in DM patients with the increased risk of respiratory infections being linked to a compromised innate immune function. Nonetheless, temporary hyperglycemia may also partially alter the innate immune response to infection (76). Anyway, it is doubtless that DM patients are more prone to develop infectious diseases due to impaired immune system function (77). Moreover, DM patients with DKD have a chronic systemic inflammation resulting from a reduced immune system status that can lead to infectious complications, and together these may determine the risk of disease and death (78).

\section{DIABETES COMPLICATIONS}

Increasing evidence states that DM-derived complications not only depict the disease severity, but also that such patients often have enhanced death rates that further justify the fact that DM is a key predictor in COVID-19 prognosis with DM severity being directly related to a bad prognosis (25). Reports also show that bad glycemic control, for example, evidenced by an increase in HbAlc, is importantly related to a higher risk to different infections $(79,80)$. Nonetheless, hyperosmolar hyperglycemic state (HHS) and DKA are still considered the most acute metabolic complications of DM, which are generally triggered by infection. Moreover, it is known that viral infection is tagged to precipitate the acute hyperglycemic issues in uncontrolled DM patients, but there is still a paucity of scientific evidence regarding this association (81). Zhang et al. (82) state that COVID-19 patients with DM are more prone to generate severe subtypes, including acute respiratory disease (ARDS) complications and acute cardiac injury that occurs due to mechanical ventilation and antibiotic treatment.

\section{Diabetes and Hypertension}

Globally, hypertension is viewed as one of the most generalized diseases and comorbidities in DM patients and considered as a silent killer (83). Published 2020 studies from China’s Wuhan province show that patients with hypertension and DM are overrepresented among the sickest COVID-19 patients and those susceptible to the disease $(5,63)$. The increased rate of hypertensive patients with SARS-CoV-2 is reported in a study with 41 patients found in Wuhan hospital (84) although a larger analysis of 138 hospitalized patients also report a similar outcome (40). Similarly, a study conducted in Jinyintan Hospital and Wuhan Pulmonary Hospital among 191 patients with the novel coronavirus found hypertension in $58(30 \%)$ patients, $26(48 \%)$ did not survive the viral infection, and 32 (23\%) survived (45). Another study performed in Switzerland found that hypertensive patients (23.7\%) with cerebrovascular disorders (22\%) and diabetes (22\%) were the most striking comorbidities (65). Recent findings also point out that the CV system is the second target system of the virus besides the lungs. Therefore, hypertension is linked to poor clinical outcomes in COVID-19 patients, and current ACEIs or ARBs should not be discontinued $(85,86)$.

\section{Diabetes and Endothelial Dysfunction}

DM is typically characterized by endothelial dysfunction apart from hyperglycemia and microcirculatory impairment (87). More than one third of newly diagnosed T2DM patients may have microvascular disease (88). The bad blow of endothelial impairment involves fibrinolysis, vasodilation dysregulation, and anti-aggregation, which typically leads to macrovascular 
disorders (81). Nevertheless, the evidence of microvascular impairment in one organ is a key indicator of systemic damage. There is evidence that such complications derive from microvascular lung diseases of DM ("diabetic lung") (89). Furthermore, atherosclerosis, endothelial impairment, and vascular inflammation are also involved in the pathogenicity of other chronic disorders, such as CV diseases and hypertension (90). Indeed, endothelial dysfunction in DM patients with COVID-19 might be due to direct invasion of vascular endothelial cells by SARS-CoV-2 through endothelial ACE2 (91). As well, the high levels of pro-inflammatory cytokines and the development of cytokine storm (CS) in severe COVID-19 patients may cause endothelial injury and boost the development of endothelial dysfunctions (92).

\section{Diabetes and Thrombosis}

Coagulation dysfunction is also reported in severe COVID-19 patients (93) with fatal cases presenting diffuse microvascular thrombosis, which is suggestive of a thrombogenic microangiopathy (94), In T2DM, aside from the marked inflammatory stage, an imbalance also exists between coagulation and fibrinolysis and also enhances clotting factor levels and relative fibrinolytic system stoppage (72). T2DM and insulin resistance are known to be related to endothelial cell dysfunction and increased platelet activation and aggregation. These abnormal changes foster the generation of hypercoagulable prothrombosis. Guo et al. (25) posit that, during the inflammatory storm, the D-dimer rises geometrically. It is an outcome of inflammation activating plasmin during the early stage. However, as inflammation goes on in hypoxia-induced molecules, which can trigger direct thrombin and activate monocyte-macrophages, which can also emit tissue factors in masses and open the pathway of exogenous coagulation, this results in a general state of hypercoagulability. For example, Guo et al. (25) found that the level of FIB and D-dimer increased greatly in DM patients, which is an indicator of prone hypercoagulable state as compared to non-DM patients. McFadyen et al. (95) reveal that SARS-CoV-2-induced endothelial dysfunction may lead to immune-related thrombosis due to both platelet and complement activations so that the use of anti-thrombotic agents, such as heparin and dipyridamole, may prevent these complications in COVID-19 patients.

\section{Diabetes and Kidney Disease}

Acute kidney injury (AKI) has been found in $<20 \%$ of critically sick and COVID-19 patients with this finding being supported by data from China (63), Italy (96), and the United States (97). A study carried out in 2020 found that kidneys have an increased vulnerability to ACE2 expression-based destruction (98), and in addition, kidney disease is a common DM-related clinical complication. Worldwide, more than 2 million individuals receive dialysis therapy, and up to half a million individuals are receiving maintenance dialysis in the United States, which poses a greater danger for the acquisition of SARS-CoV-2 infection. The CDC and the American Society of Nephrology (ASN) have compiled best practices for in-center dialysis (99). Marked changes in immune system function have been stated in patients with kidney-related problems; nonetheless, despite immune system impairment, meticulous attention should be paid on the uremic state because the excessive oxidative stress status caused by excess toxin retention and gathering of synthesized products of oxidation can exacerbate the clinical status in infected patients (72). A study recorded that endothelial damage is normal in 26 patients with SARS-CoV-2 renal histopathology without interstitial inflammatory infiltration (100). However, so far, there are still not certain reports with respect to the kidneys. The direct mechanism in viral infection includes syndrome of CS via targeted viral renal tubular cell destruction, and sepsis pathways have been investigated (101). Presently, the major expression of renal destruction in SARS-CoV-2-infected patients looks to be acute although certain conditions of proteinuria/hematuria and macroalbuminuria may be interrelated to endothelial cell impairment found in such patients (102).

\section{Chest Tomography (CT) Imaging and Biochemical Tests of Diabetic Patients}

In DM patients, a chest CT scan usually depicts groundglass opacifications with abnormalities that are united or not. Involvement in normal lobes can also be seen bilaterally with peripheral features of COVID-19 (103). Moreover, although normal CT images can also be found in some confirmed cases (104), abnormal images have also been seen in asymptomatic patients. For instance, Guo et al. (25) report that the DM patients' group had an increase in the CT image score when compared with those non-DM who have COVID-19 pneumonia with clinical status being also more serious than in those without DM. Into the bargain, the retrospective study by Wang et al. (105), involving 307 COVID-19 patients, shows that early definitive diagnosis could be grasped by age-related clinical and CT scan findings. Moreover, lung CT scan findings were correlated with COVID-19 severity and development of acute ischemic stroke in T2DM patients with COVID-19 (106).

Regarding biochemical outcomes in such patients, some authors have already stated that few enzymes serving as indicators are raised aberrantly in the blood of viral pneumonia patients, including $\alpha$-hydroxybutyrate dehydrogenase $(\mathrm{HBDH})$, gamma glutamyltransferase (GGT), lactate dehydrogenase $(\mathrm{LDH})$, and alanine aminotransferase (ALT), which shows myocardium, liver, and kidney injury. This outcome is in consonance with the excessive frequency of viral receptors (ACE2) and may partly explain why death occurred in some patients with multiple organ failure $(107,108)$.

\section{Blood Picture of Diabetic Patients With COVID-19}

SARS-CoV-2-infected patients commonly depict lymphocytopenia on entry and, to a limited degree, leukopenia and thrombocytopenia, more conspicuous in those with severe disease status (5). Elevated pro-inflammatory cytokine levels, which include, among others, C-reactive protein (CRP), interleukin (IL)-6, and enhanced coagulation activity, shown by higher d-dimer concentrations, have also been correlated with disease severity (45). Furthermore, DM patients had greater neutrophils, IL-6, white cells, LDH, IL-2R, CRP, IL-8, D-dimer, and N-terminal pro-B-type natriuretic peptide (NT-proBNP) 
levels and lower lymphocyte counts. Taken together, these outcomes indicate an increased response to pro-inflammatory cytokines compared with non-DM patients (58). Moreover, the serum levels of some inflammation-related biomarkers are higher in DM when compared with non-DM individuals, such as IL-6, ESR, CRP, and serum ferritin. Additionally, a pronounced raise in serum ferritin levels is an indicator of monocyte-macrophage activation, a crucial part of the inflammatory storm. Taken together, these results show that patients with an inflammatory storm are more prone to rapid destruction by COVID-19 (25).

\section{Inflammatory Storm in Diabetic Patients With SARS-CoV-2 Infection}

A recently published report, analyzing 138 hospitalized SARS-CoV-2 infected patients, observed that CS-associated neutrophilia triggered by virus invasion and coagulation opening similar to the longer response of inflammation and acute kidney injury has a similar negative impact on SARS-CoV-2, which may be related to the death rate of infected patients (40). A study report that severe SARS-CoV-2 infected patients with pneumonia have a significantly reduced lymphocyte count with high levels of inflammatory factors, especially IL-6 (78). Guo et al. (25) report that, compared with non-DM patients, in DM individuals, the total absolute lymphocyte count in peripheral blood is greatly reduced, and the neutrophil absolute count shows a remarkable increase. Therefore, a high neutrophil-lymphocyte ratio (NLR) in DM patients may increase COVID-19 severity because high NLR is regarded as a poor prognostic factor linked to COVID-19 severity and mortality (109).

\section{CONTROL OF DM PATIENTS WITH COVID-19}

Regarding the management of DM patients with COVID-19, Guo et al. (25) in their study suggest that, whether there is interference or not from other comorbidities, DM patients with viral pneumonia present a more serious status when compared with non-DM ones, stated through organ destruction and inflammatory factor evaluation, that can lead to a complicated prognosis. In the face of such findings, more intensive care should be given to DM patients in case of rapid deterioration. Nevertheless, careful attention should be given to those with nephropathic DM because such patients are at greater risk of viral infection, serious complications, and even death $(110,111)$.

Current CDC guidance for preventing SARS-CoV-2 infection in $\mathrm{DM}$ individuals reveals no differences from the general population, but awareness that DM can lead to a high risk of serious illness should make it easier for healthcare providers to monitor such patients with symptoms of viral infection (i.e., fever and breath shortness) (112). Thus, the role of doctors who give suggestions to DM patients is of crucial importance as they should provide information on extra precaution measures, including social distancing and hand washing toward preventing them from SARS-CoV-2 infection (97). In addition, there should be improved surveillance in DM outpatients for the viral agent, and the starting point for testing this viral infection in such patients should be reduced (64). For instance, Whyte et al. (113) conclude that endothelial dysfunction and microvascular disease may depict as absent a pathophysiological relationship that indicates susceptible populations and may involve specific therapy. Moreover, Zhang et al. (76) postulate that more intensive vigilance and therapy should be considered in DM patients infected with the viral agent, most especially in geriatric ones and in those with preexisting comorbidities. In addition, DM patients are associated with increased mortality and higher disease severity. In a systematic review, Huang et al. (76) show that DM is linked to higher COVID-19 severity, high mortality, disease progression, and development of ARDS.

\section{Glycemic Control of DM Patients With COVID-19}

So far, only a small percentage of experimental studies have addressed the role of hyperglycemia in the respiratory system of individuals with COVID-19 (59). However, studies have reported that hyperglycemia can heighten the glucose concentrations in airway secretions (54). In addition, hyperglycemia can also have a negative impact on pulmonary activity so that respiratory dysfunction triggered by the influenza virus is exacerbated in DM patients (64). DM is related to many changes in lung structure, and these include supplemented vasculature permeability and a relaxed alveolar epithelium in animal models with the disease (114). Glycemic regulation may have a relevant impact on clinical outcomes in individuals with coexistent viral respiratory diseases and DM, such as COVID-19 (65). It has been shown that hyperglycemia and SARS-CoV-2 infection interact in a vicious cycle, in which hyperglycemia induces ACE2 glycation that increases affinity to the SARS-CoV-2. Thus, severe SARS$\mathrm{CoV}-2$ infection-induced insulin resistance and pancreatic $\beta$ cell damage by high levels of pro-inflammatory cytokines can also lead to hyperglycemia (115). Thus, strict control of blood glucose in DM patients with COVID-19 is mandatory to prevent life-threatening complications.

\section{Control of Hypertension in DM Patients With COVID-19}

The coexistence of DM and hypertension requires judicious control of blood pressure increases. A distinct caveat in hypertension therapy in such patients shows that coronaviruses can bind to cells via ACE2, which means that patients who receive therapy with drugs of pharmacological origin that rise ACE2 levels may be put in jeopardy (65). The prevalence of hypertension and CV diseases is clinically relevant in COVID-19 patients, particularly in the elderly with DM. Based on animal models, some concerns have been raised on RAS inhibitors, particularly ARBs, as they can affect ACE2 expression despite there being no clinical evidence that they should be restricted or momentarily obsolete in COVID19 patients (53). Thus, the European Society of Cardiology (ESC), the American College of Cardiology, the American Heart Association and the Heart Failure Society of America (ACC/AHA-HFSA), and the American Society of Hypertension (ASH) have issued policy statements that strongly recommend 
DM patients continue therapy with their usual antihypertensive treatment as no empirical reports exist suggesting that therapy with ACE inhibitors or ARBs should be stopped due to SARS-CoV-2 infection. Nonetheless, the issues that cannot be recognized in relation to COVID-19 and DM are significant and numerous (64).

\section{Control of Neuroendocrine Diseases in COVID-19 Patients With DM}

A study by Kaiser et al. (116) found that, in COVID-19 patients, those with pituitary or other neuroendocrine disorders need to be addressed. Patients that have a shortage of primary adrenaline may develop DM insipidus, which further complicate both electrolyte and fluid disorders. Thus, close control and judicious replacement of water and electrolytes to avoid hyponatremia or hypernatremia is crucial to block the high loss of insensitive fluid linked to fever and tachypnea, combined with impaired fluid intake and altered levels of consciousness (117). Indeed, DDP4 inhibitors reduce mortality and COVID-19 severity in DM patients through attenuation of SARS-CoV-2 entry and associated pro-inflammatory cytokine release (118).

\section{Control of Kidney Diseases in Diabetic Patients With COVID-19}

ACEi/ARB therapy use has no have negative impact on COVID19 morbimortality in synergy with CV disorders (119). D’Marco et al. (72), testing a hypothetical assertion, showed a worsening of DKD that could result in the progression of a serious CKD stage, need for renal replacement, and even death. The authors also postulate that the actual observations support the assertion that reduced immune system defenses and other kidney-associated factors make DM patients more susceptible to infections by certain infectious agents (72).

\section{Clinical Medication of DM Patients With COVID-19}

Recent studies raise the hypothesis that both the treatment course and prognosis of COVID-19 should be grouped, depending on the presence or absence of comorbidities into types A, B, and C. Type A refers to patients with the virus and pneumonia and without comorbidities, type B patients with the virus and pneumonia and comorbidities, and type $\mathrm{C}$ represents COVID19 patients with pneumonia and multiorgan dysfunction (120). In China, Yan et al. (121) studied the clinical features and outcomes in 48 patients with extreme DM and SARS-CoV2 and compared them with 145 severe COVID-19 patients hospitalized but without DM. As main findings, the authors show that DM patients with serious viral infection had a more severe response due to inflammation and were more prone to require mechanical ventilation and experience death (and survival delay) when compared with non-DM. Regarding clinical medication, the authors state that the insulin dose increased after the patient was infected with SARS-CoV-2, which depicts that the viral agent plays a direct role in glucose metabolism of such patients. Consequently, glucose metabolic dysfunction triggers DM and then impacts pneumonia severity, acting as an amplification loop (25). A study carried out in more than 500 COVID-19 patients revealed that hyperglycemia has often been temporary and usually addressed in most patients after hospital discharge (63). For such hospitalized patients, it is imperative to ensure an excellent glycemic control and look for blood sugar results of $4-10 \mathrm{mmol} / \mathrm{L}$ to halt bad results $(65,66)$. Thus, when reacting to the novel coronavirus pandemic, policies and actions need to involve DM when health inequities are not triggered (49). Indeed, it is reported that uncontrolled or poorly regulated hyperglycemia for any reason, including DM or stress hyperglycemia, is linked to poor outcomes in COVID-19 patients (122). Therefore, strict glucose monitoring and control is advisable in severely affected COVID-19 patients even in nonDM ones $(123,124)$. For example, in India, the T2DM treatment with hydroxychloroquine has been approved as an alternative for patients with a non-controlled DM with other hypoglycemic agents (i.e., stable-dose insulin therapy with metformin and glimepiride) (125). Moreover, despite inflammation being linked to impaired glucose regulation, the underlying mechanism of the hypoglycemic effect of hydroxychloroquine is still not clear (106).

Micallef et al. (126) indicated that corticosteroid therapy could worsen a patient's condition and that non-steroidal antiinflammatory drugs, such as ibuprofen, might increase the risk of developing a complicated type of the disease. Indeed, according to the updated clinical guideline, the WHO recommends the use of corticosteroids in severe cases of SARS-CoV-2 infection (127). It is reported that respiratory viral infections are linked to development of DM due to autoimmune pancreatic $\beta$-cells injury (128). Specifically, in COVID-19 patients, SARS-CoV-2 may trigger development of DM due to direct pancreatic $\beta$ cell injury of SARS-CoV-2 due to a higher expression of ACE2, a receptor for this virus, or indirectly through induction of insulin resistance triggered by SARS-CoV-2-induced oxidative stress (129). Likewise, acute pancreatitis and secondary DM have been reported as an adverse effect of ritonavir and lopinavir, commonly used drugs for the treatment of COVID-19 (130). Likewise, the constant use of ARBs and ACEIs are associated with immunomodulatory properties and reduced pulmonary and systemic inflammatory reactions due to delayed cytokines $(131,132)$. SARS-CoV-2 may have a direct effect on endothelial cells so that other drugs may also be successful in the treatment of COVID-19 patients via their positive impact on endothelial cells, including $\alpha 1$-adrenergic receptor blockers (e.g., doxazosin) (133), modulators of Sigma receptors (134), metformin (135), indomethacin (136), endothelin receptor antagonists (e.g., bosentan) (137), and heparin and low-molecular weight heparin (LMWH) (138). These drugs, which are often used by DM patients, particularly metformin, reduces endothelial dysfunction and associated complications.

APN01 is a recombinant human ACE2 produced by APEIRON to treat ARDS, pulmonary arterial hypertension, and acute lung injury; briefly, it works by delaying the virus entry and spread and, therefore, may be of high benefit although the clinical trials are still ongoing (100). Indeed, recombinant human ACE2 increases metabolism of vasoconstrictor Ang II to vasodilator Ang1-7, which attenuates development of ARDS (139). 
In this sense, the optimal therapy for these patients should derive from an approach involving a consortium of multidisciplinary members, including specialists in infectious diseases, emergency medicine, endocrinology, and respiratory function. Furthermore, backup from exercise rehabilitation specialists and nutritionists may be needed during a longer period of recovery and hospital stay (140). Finally, and regarding therapy, although there are different clinical trials and studies ongoing to assess the efficacy and safety of possible therapeutic alternatives, such as the use of chloroquine phosphate, lopinavir/ritonavir, remdesivir, interferon, tocilizumab, ribavirin, and arbidol, among others (110), no drug against SARS-CoV-2 has been developed and officially approved so far (141).

\section{CONCLUSION}

In short, $\mathrm{DM}$ patients are at a higher risk of developing the severe form of COVID-19 as a consequence of the presence of cardio-metabolic and immunological disorder, including insulin resistance, prolonged hyperglycemia, and hyperinflammation despite other comorbidities, such as hypertension, also maybe

\section{REFERENCES}

1. Al-Kuraishy HM, Al-Gareeb AI. From SARS-CoV to nCoV2019: ruction and argument. Arch Clin Infect Dis. (2020) 15:1-2. doi: 10.5812/archcid.102624

2. Andersen KG, Rambaut A, Lipkin WI, Holmes EC, Garry RF. The proximal origin of SARS-CoV-2. Nat Med. (2020) 26:450-2. doi: 10.1038/s41591-020-0820-9

3. Al-kuraishy HM, Al-Maiahy TJ, Al-Gareeb AI, Musa RA, Ali ZH. COVID-19 pneumonia in an Iraqi pregnant woman with preterm delivery. Asian Pac J Reprod. (2020) 9:156. doi: 10.4103/2305-0500.282984

4. Becerra-Flores M, Cardozo T. SARS-CoV-2 viral spike G614 mutation exhibits higher case fatality rate. Int J Clin Pract. (2020) 74:e13525. doi: 10.1111/ijcp.13525

5. Al-Kuraishy HM, Al-Naimi MS, Lungnier CM, Al-Gareeb AI. Macrolides and COVID-19: An optimum premise. Biomed Biotechnol Res J. (2020) 4:189. doi: 10.4103/bbrj.bbrj_103_20

6. Lugnier C, Al-Kuraishy HM, Rousseau E. PDE4 inhibition as a therapeutic strategy for improvement of pulmonary dysfunctions in Covid-19 and cigarette smoking. Biochem Pharmacol. (2021) 185:114431. doi: 10.1016/j.bcp.2021.114431

7. Adhikari SP, Meng S, Wu Y-J, Mao Y-P, Ye R-X, Wang Q-Z, et al. Epidemiology, causes, clinical manifestation and diagnosis, prevention and control of coronavirus disease (COVID-19) during the early outbreak period: a scoping review. Infect Dis Poverty. (2020) 9:112 doi: 10.1186/s40249-020-00646-x

8. Zou L, Ruan F, Huang M, Liang L, Huang H, Hong Z, et al. SARS-CoV-2 viral load in upper respiratory specimens of infected patients. $N$ Engl J Med. (2020) 382:1177-9. doi: 10.1056/NEJMc2001737

9. Liu Y, Yan L-M, Wan L, Xiang T-X, Le A, Liu J-M, et al. Viral dynamics in mild and severe cases of COVID-19. Lancet Infect Dis. (2020) 20:6567. doi: 10.1016/S1473-3099(20)30232-2

10. Rothe C, Schunk M, Sothmann P, Bretzel G, Froeschl G, Wallrauch C, et al. Transmission of 2019-nCoV infection from an asymptomatic contact in Germany. N Engl J Med. (2020) 382:970-1. doi: 10.1056/NEJMc2001468

11. Al-Kuraishy HM, Sami OM, Hussain NR, Al-Gareeb AI. Metformin and/or vildagliptin mitigate type II diabetes mellitus inducedoxidative stress: the intriguing effect. J Adv Pharm Technol Res. (2020) 11:142. doi: 10.4103/japtr.JAPTR_18_20 boosting the risk. However, and noteworthy, SARS-CoV-2 may cause transient hyperglycemia even in non-DM patients as it is able to induce insulin resistance and/or damage to pancreatic $\beta$ cells. Thus, it is essential to ensure strict glucose monitoring in COVID-19 patients with DM to prevent the occurrence of lifethreatening complications. Regarding pharmacotherapy in DM, the use of DDP4 inhibitors, mainly sitagliptin, have demonstrated noteworthy anti-inflammatory and anti-SARS-CoV-2 activity, so their use seems to be extremely useful in the management of DM patients with COVID-19.

\section{AUTHOR CONTRIBUTIONS}

AM, VO, DH, IR, OA, NR-P, AZ-B, MS, HH, NC-M, and GB wrote and revised the paper. All authors have read and agreed to the published version of the manuscript.

\section{ACKNOWLEDGMENTS}

NC-M acknowledges the Portuguese Foundation for Science and Technology under the Horizon 2020 Program (PTDC/PSIGER/28076/2017).

12. Rasheed HA, Al-Kuraishy HM, Al-Gareeb AI, Hussien NR, Al-Nami MS Effects of diabetic pharmacotherapy on prolactin hormone in patients with type 2 diabetes mellitus: Bane or Boon. J Adv Pharm Technol Res. (2019) 10:163. doi: 10.4103/japtr.JAPTR_65_19

13. Al-Kuraishy HM, Al-Gareeb AI, Shams HA, Al-Mamorri F. Endothelial dysfunction and inflammatory biomarkers as a response factor of concurrent coenzyme Q10 add-on metformin in patients with type 2 diabetes mellitus. J Lab Phys. (2019) 11:317. doi: 10.4103/JLP.JLP_123_19

14. Muralidharan G, Rao GH. Oxygen as a therapeutic drug: hyperbaric oxygen therapy. Biomed Pharmacol J. (2020) 13:521-8. doi: 10.13005/bpj/ 1913

15. Pearson-Stuttard J, Blundell S, Harris T, Cook DG, Critchley J. Diabetes and infection: assessing the association with glycaemic control in population-based studies. Lancet Diabetes Endocrinol. (2016) 4:14858. doi: 10.1016/S2213-8587(15)00379-4

16. Xia C, Rao X, Zhong J. Role of $\mathrm{T}$ lymphocytes in type 2 diabetes and diabetes-associated inflammation. J Diabetes Res. (2017) 2017:6494795. doi: 10.1155/2017/6494795

17. Hodgson K, Morris J, Bridson T, Govan B, Rush C, Ketheesan $\mathrm{N}$. Immunological mechanisms contributing to the double burden of diabetes and intracellular bacterial infections. Immunology. (2015) 144:17185. doi: 10.1111/imm.12394

18. Muller L, Gorter K, Hak E, Goudzwaard W, Schellevis F, Hoepelman A, et al. Increased risk of common infections in patients with type 1 and type 2 diabetes mellitus. Clin Infect Dis. (2005) 41:281-8. doi: 10.1086/431587

19. Yang J, Feng Y, Yuan M, Yuan S, Fu H, Wu B, et al. Plasma glucose levels and diabetes are independent predictors for mortality and morbidity in patients with SARS. Diabetic Med. (2006) 23:6238. doi: 10.1111/j.1464-5491.2006.01861.x

20. Schoen K, Horvat N, Guerreiro NF, de Castro I, de Giassi KS. Spectrum of clinical and radiographic findings in patients with diagnosis of H1N1 and correlation with clinical severity. BMC Infect Dis. (2019) 19:18 doi: 10.1186/s12879-019-4592-0

21. Banik GR, Alqahtani AS, Booy R, Rashid H. Risk factors for severity and mortality in patients with MERS-CoV: analysis of publicly available data from Saudi Arabia. Virol Sin. (2016) 31:81-4. doi: 10.1007/s12250-015-3679-z

22. Erener S. Diabetes, infection risk and COVID-19. Mol Metab. (2020) 39:101044. doi: 10.1016/j.molmet.2020.101044 
23. Kuba K, Imai Y, Rao S, Gao H, Guo F, Guan B, et al. A crucial role of angiotensin converting enzyme 2 (ACE2) in SARS coronavirus-induced lung injury. Nat Med. (2005) 11:875-9. doi: 10.1038/nm1267

24. Wrapp D, Wang N, Corbett KS, Goldsmith JA, Hsieh C-L, Abiona O, et al. Cryo-EM structure of the 2019-nCoV spike in the prefusion conformation. Science. (2020) 367:1260-3. doi: 10.1126/science.abb2507

25. Patel VB, Zhong J-C, Grant MB, Oudit GY. Role of the ACE2/angiotensin 1-7 axis of the renin-angiotensin system in heart failure. Circ Res. (2016) 118:1313-26. doi: 10.1161/CIRCRESAHA.116.307708

26. Guo W, Li M, Dong Y, Zhou H, Zhang Z, Tian C, et al. Diabetes is a risk factor for the progression and prognosis of COVID-19. Diabetes Metab Res Rev. (2020) 36:1-9. doi: 10.1002/dmrr.3319

27. Sommerstein R, Kochen MM, Messerli FH, Gräni C. Coronavirus Disease 2019 (COVID-19): do angiotensin-converting enzyme inhibitors/angiotensin receptor blockers have a biphasic effect? J Am Heart Assoc. (2020) 9:e016509. doi: 10.1161/JAHA.120.016509

28. Drucker DJ. Coronavirus infections and type 2 diabetes-shared pathways with therapeutic implications. Endocr Rev. (2020) 41:bnaa011. doi: 10.1210/endrev/bnaa011

29. Iacobellis G. COVID-19 and diabetes: can DPP4 inhibition play a role? Diabetes Res Clin Pract. (2020) 162:108125. doi: 10.1016/j.diabres.2020.108125

30. Karagiannis T, Paschos P, Paletas K, Matthews DR, Tsapas A. Dipeptidyl peptidase-4 inhibitors for treatment of type 2 diabetes mellitus in the clinical setting: systematic review and meta-analysis. BMJ. (2012) 344:e1369. doi: 10.1136/bmj.e1369

31. Amori RE, Lau J, Pittas AG. Efficacy and safety of incretin therapy in type 2 diabetes: systematic review and meta-analysis. JAMA. (2007) 298:194206. doi: 10.1001/jama.298.2.194

32. Yang W, Cai X, Han X, Ji L. DPP-4 inhibitors and risk of infections: a metaanalysis of randomized controlled trials. Diabetes Metab Res Rev. (2016) 32:391-404. doi: 10.1002/dmrr.2723

33. Bassendine MF, Bridge SH, McCaughan GW, Gorrell MD. COVID-19 and comorbidities: a role for dipeptidyl peptidase 4 (DPP4) in disease severity?. J Diabetes. (2020) 12:649-58. doi: 10.1111/1753-0407.13052

34. Zhou P, Yang X-L, Wang X-G, Hu B, Zhang L, Zhang W, et al. A pneumonia outbreak associated with a new coronavirus of probable bat origin. Nature. (2020) 579:270-3. doi: 10.1038/s41586-020-2012-7

35. Matsuyama S, Nao N, Shirato K, Kawase M, Saito S, Takayama I, et al. Enhanced isolation of SARS-CoV-2 by TMPRSS2-expressing cells. Proc Natl Acad Sci. (2020) 117:7001-3. doi: 10.1073/pnas.2002589117

36. Sungnak W, Huang N, Bécavin C, Berg M, Queen R, Litvinukova M, et al. SARS-CoV-2 entry factors are highly expressed in nasal epithelial cells together with innate immune genes. Nat Med. (2020) 26:6817. doi: 10.1038/s41591-020-0868-6

37. Chen Z, Mi L, Xu J, Yu J, Wang X, Jiang J, et al. Function of HAb18G/CD147 in invasion of host cells by severe acute respiratory syndrome coronavirus. $J$ Infect Dis. (2005) 191:755-60. doi: 10.1086/427811

38. Tortorici MA, Walls AC, Lang Y, Wang C, Li Z, Koerhuis D, et al. Structural basis for human coronavirus attachment to sialic acid receptors. Nat Struct Mol Biol. (2019) 26:481-9. doi: 10.1038/s41594-019-0233-y

39. Jaeckel E, Manns M, Von Herrath M. Viruses and diabetes. Ann N Y Acad Sci. (2002) 958:7-25. doi: 10.1111/j.1749-6632.2002.tb02943.x

40. Jali M, Shankar P. Transient diabetes following chicken pox. J Assoc Phys India. (1990) 38:663-4.

41. Yang J-K, Lin S-S, Ji X-J, Guo L-M. Binding of SARS coronavirus to its receptor damages islets and causes acute diabetes. Acta Diabetol. (2010) 47:193-9. doi: 10.1007/s00592-009-0109-4

42. Wang D, Hu B, Hu C, Zhu F, Liu X, Zhang J, et al. Clinical characteristics of 138 hospitalized patients with 2019 novel coronavirus-infected pneumonia in Wuhan, China. JAMA. (2020) 323:1061-9. doi: 10.1001/jama.2020.1585

43. Mehra MR, Desai SS, Kuy S, Henry TD, Patel AN. Cardiovascular disease, drug therapy, and mortality in COVID-19. N Engl J Med. (2020) 382:e102. doi: 10.1056/NEJMoa2007621

44. Tentolouris A, Eleftheriadou I, Athanasakis K, Kyriopoulos J, Tsilimigras DI, Grigoropoulou P, et al. Prevalence of diabetes mellitus as well as cardiac and other main comorbidities in a representative sample of the adult Greek population in comparison with the general population. Hellenic J Cardiol. (2018) 61:15-22. doi: 10.1016/j.hjc.2018.04.008
45. Covid C, Team R. Severe outcomes among patients with coronavirus disease 2019 (COVID-19)-United States, February 12-March 16, 2020. MMWR Morb Mortal Wkly Rep. (2020) 69:343-6. doi: 10.15585/mmwr.mm6912e2

46. Al-Sabah SK, Al-Haddad M, Al Youha S, Jamal MH, AlMazeedi S. COVID19: impact of obesity and diabetes in disease severity. medRxiv. (2020) 10:e12414. doi: 10.1111/cob.12414

47. Zhou F, Yu T, Du R, Fan G, Liu Y, Liu Z, et al. Clinical course and risk factors for mortality of adult inpatients with COVID-19 in Wuhan, China: a retrospective cohort study. The lancet. (2020) 395:105462. doi: 10.1016/S0140-6736(20)30566-3

48. Klekotka RB, Mizgała E, Król W. The etiology of lower respiratory tract infections in people with diabetes. Adv Respir Med. (2015) 83:4018. doi: 10.5603/PiAP.2015.0065

49. Choi WS, Kang C-I, Kim Y, Choi J-P, Joh JS, Shin H-S, et al. Clinical presentation and outcomes of Middle East respiratory syndrome in the Republic of Korea. Infect Chemother. (2016) 48:118-26. doi: 10.3947/ic.2016.48.2.118

50. Carey IM, Critchley JA, DeWilde S, Harris T, Hosking FJ, Cook DG. Risk of infection in type 1 and type 2 diabetes compared with the general population: a matched cohort study. Diabetes Care. (2018) 41:51321. doi: $10.2337 / \mathrm{dc} 17-2131$

51. Coppell KJ, Hall RM, Downie M, Fraser SK, Garrett M, Jefferies CA, et al. Diabetes and COVID-19-the meeting of two pandemics: what are the concerns? N Z Med J. (2020) 133:85-7.

52. Al Heialy S, Hachim MY, Senok A, Abou Tayoun A, Hamoudi R, Alsheikh-Ali A, et al. Regulation of angiotensin converting enzyme 2 (ACE2) in obesity: implications for COVID-19. Front Physiol. (2020) 11:555039 doi: 10.1101/2020.04.17.046938

53. Muniyappa R, Gubbi S. COVID-19 pandemic, coronaviruses, and diabetes mellitus. Am J Physiol Endocrinol Metab. (2020) 318:E736-41. doi: 10.1152/ajpendo.00124.2020

54. Kumar A, Arora A, Sharma P, Anikhindi SA, Bansal N, Singla V, et al. Is diabetes mellitus associated with mortality and severity of COVID-19? A meta-analysis. Diabetes Metab Syndrome Clin Res Rev. (2020) 14:53545. doi: 10.1016/j.dsx.2020.04.044

55. Huang Y-T, Lee Y-C, Hsiao C-J. Hospitalization for ambulatory-caresensitive conditions in Taiwan following the SARS outbreak: a populationbased interrupted time series study. J Formosan Med Assoc. (2009) 108:38694. doi: 10.1016/S0929-6646(09)60082-6

56. Chan-Yeung M, Xu RH. SARS: epidemiology. Respirology. (2003) 8:S9S14. doi: 10.1046/j.1440-1843.2003.00518.x

57. Morra ME, Van Thanh L, Kamel MG, Ghazy AA, Altibi AM, Dat LM, et al. Clinical outcomes of current medical approaches for Middle East respiratory syndrome: a systematic review and meta-analysis. Rev Med Virol. (2018) 28:e1977. doi: 10.1002/rmv.1977

58. Li B, Yang J, Zhao F, Zhi L, Wang X, Liu L, et al. Prevalence and impact of cardiovascular metabolic diseases on COVID-19 in China. Clin Res Cardiol. (2020) 109:531-8. doi: 10.1007/s00392-020-01626-9

59. Wang A, Zhao W, Xu Z, Gu J. Timely blood glucose management for the outbreak of 2019 novel coronavirus disease (COVID19) is urgently needed. Diabetes Res Clin Pract. (2020) 162:108118. doi: 10.1016/j.diabres.2020.108118

60. Chow N, Fleming-Dutra K, Gierke R, Hall A, Hughes M, Pilishvili T, et al. Preliminary estimates of the prevalence of selected underlying health conditions among patients with coronavirus disease 2019-United States, February 12-March 28, 2020. MMWR Morb Mortal Wkly Rep. (2020) 69:3826. doi: 10.15585/mmwr.mm6913e2

61. Shenoy A, Ismaily M, Bajaj M. Diabetes and Covid-19: a global health challenge. BMJ Spec J. (2020) 8:1-2. doi: 10.1136/bmjdrc-2020-001450

62. Wu Z, McGoogan JM. Characteristics of and important lessons from the coronavirus disease 2019 (COVID-19) outbreak in China: summary of a report of 72314 cases from the Chinese Center for Disease Control and Prevention. JAMA. (2020) 323:1239-42. doi: 10.1001/jama.2020.2648

63. Umpierrez GE, Isaacs SD, Bazargan N, You X, Thaler LM, Kitabchi AE. Hyperglycemia: an independent marker of in-hospital mortality in patients with undiagnosed diabetes. J Clin Endocrinol Metab. (2002) 87:97882. doi: 10.1210/jcem.87.3.8341

64. Van den Berghe G, Wouters PJ, Bouillon R, Weekers F, Verwaest C, Schetz $\mathrm{M}$, et al. Outcome benefit of intensive insulin therapy in the critically 
ill: Insulin dose versus glycemic control. Crit Care Med. (2003) 31:35966. doi: 10.1097/01.CCM.0000045568.12881.10

65. Zhu L, She ZG, Cheng X, Qin JJ, Zhang XJ, Cai J, et al. Association of blood glucose control and outcomes in patients with COVID19 and pre-existing type 2 diabetes. Cell Metab. (2020) 31:106877. doi: 10.1016/j.cmet.2020.04.021

66. Gates B. Responding to Covid-19-a once-in-a-century pandemic? N Engl J Med. (2020) 382:1677-9. doi: 10.1056/NEJMp2003762

67. Yang X, Yu Y, Xu J, Shu H, Liu H, Wu Y, et al. Clinical course and outcomes of critically ill patients with SARS-CoV-2 pneumonia in Wuhan, China: a single-centered, retrospective, observational study. Lancet Respir Med. (2020) 8:475-81. doi: 10.1016/S2213-2600(20)30079-5

68. Tsoukas MA, Farr OM, Mantzoros CS. Leptin in congenital and HIV-associated lipodystrophy. Metabolism. (2015) 64:4759. doi: 10.1016/j.metabol.2014.07.017

69. Marik PE, DePerrior SE, Ahmad Q, Dodani S. Gender-based disparities in COVID-19 patient outcomes. J Invest Med. (2021) 69:814-8. doi: 10.1136/jim-2020-001641

70. Shahid Z, Kalayanamitra R, McClafferty B, Kepko D, Ramgobin D, Patel R, et al. COVID-19 and older adults: what we know. J Am Geriatr Soc. (2020) 68:926-9 doi: 10.1111/jgs.16472

71. Fang L, Karakiulakis G, Roth M. Are patients with hypertension and diabetes mellitus at increased risk for COVID-19 infection? Lancet Respir Med. (2020) 8:e21. doi: 10.1016/S2213-2600(20)30116-8

72. Bode B, Garrett V, Messler J, McFarland R, Crowe J, Booth R, et al. Glycemic characteristics and clinical outcomes of COVID-19 patients hospitalized in the United States. J Diabetes Sci Technol. (2020) 14:81321. doi: $10.1177 / 1932296820924469$

73. Guzmán-Flores JM, López-Briones S. Cells of innate and adaptive immunity in type 2 diabetes and obesity. Gac Med Mex. (2012) 148:381-9.

74. Diao B, Wang C, Tan Y, Chen X, Liu Y, Ning L, et al. Reduction and functional exhaustion of $\mathrm{T}$ cells in patients with coronavirus disease 2019 (COVID-19). Front Immunol. (2020). 11:827. doi: 10.3389/fimmu.2020.00827

75. Kulcsar KA, Coleman CM, Beck SE, Frieman MB. Comorbid diabetes results in immune dysregulation and enhanced disease severity following MERSCoV infection. JCI Insight. (2019) 4:e131774. doi: 10.1172/jci.insight.131774

76. Huang I, Lim MA, Pranata R. Diabetes mellitus is associated with increased mortality and severity of disease in COVID-19 pneumonia-a systematic review, meta-analysis, and meta-regression. Diabetes Metab Syndrome Clin Res Rev. (2020) 14:395-403.73. doi: 10.1016/j.dsx.2020.04.018

77. Tang N, Bai H, Chen X, Gong J, Li D, Sun Z. Anticoagulant treatment is associated with decreased mortality in severe coronavirus disease 2019 patients with coagulopathy. J Thromb Haemost. (2020) 18:10949. doi: $10.1111 /$ jth.14817

78. D’Marco L, Puchades MJ, Romero-Parra M, Gorriz JL. Diabetic kidney disease and COVID-19: the crash of two pandemics. Front Med. (2020) 7:199. doi: 10.3389/fmed.2020.00199

79. Critchley JA, Carey IM, Harris T, DeWilde S, Hosking FJ, Cook DG. Glycemic control and risk of infections among people with type 1 or type 2 diabetes in a large primary care cohort study. Diabetes Care. (2018) 41:2127-35. doi: $10.2337 / \mathrm{dc} 18-0287$

80. Mor A, Dekkers OM, Nielsen JS, Beck-Nielsen H, Sørensen HT, Thomsen RW. Impact of glycemic control on risk of infections in patients with type 2 diabetes: a population-based cohort study. Am J Epidemiol. (2017) 186:227-36. doi: 10.1093/aje/kwx049

81. Kim N-y, Ha E, Moon JS, Lee Y-H, Choi EY. Response: acute hyperglycemic crises with coronavirus disease-19: case reports (Diabetes Metab J (2020) 44:349-53). Diabetes Metab J. (2020) 44:484-5. doi: 10.4093/dmj.2020.0129

82. Zhang Y, Cui Y, Shen M, Zhang J, Liu B, Dai M, et al. Comorbid diabetes mellitus was associated with poorer prognosis in patients with COVID-19: a Retrospective Cohort Study. medRxiv [Preprint]. (2020). doi: 10.1101/2020.03.24.20042358

83. Williams B, Mancia G, Spiering W, Agabiti Rosei E, Azizi M, Burnier M, et al. 2018 ESC/ESH Guidelines for the management of arterial hypertension: the Task Force for the management of arterial hypertension of the European Society of Cardiology (ESC) and the European Society of Hypertension (ESH). Eur Heart J. (2018) 39:3021-104. doi: 10.1093/eurheartj/ehy339
84. Huang C, Wang Y, Li X, Ren L, Zhao J, Hu Y, et al. Clinical features of patients infected with 2019 novel coronavirus in Wuhan, China. Lancet. (2020) 395:497-506. doi: 10.1016/S0140-6736(20)30183-5

85. Deftereos SG, Siasos G, Giannopoulos G, Vrachatis DA, Angelidis C, Giotaki SG, et al. The GReek study in the Effects of Colchicine in COvid-19 complications prevention (GRECCO-19 study): rationale and study design. Hellenic J Cardiol. (2020) 61:42-5. doi: 10.1016/j.hjc.2020.03.002

86. Schiffrin EL, Flack JM, Ito S, Muntner P, Webb RC. Hypertension and COVID-19. Am J Hypertens. (2020) 33:373-74. doi: 10.1093/ajh/hpaa057

87. Avogaro A, Albiero M, Menegazzo L, de Kreutzenberg S, Fadini GP. Endothelial dysfunction in diabetes: the role of reparatory mechanisms. Diabetes Care. (2011) 34(Suppl. 2):S285-S90. doi: 10.2337/dc11-s239

88. Palladino R, Tabak AG, Khunti K, Valabhji J, Majeed A, Millett C, et al. Association between pre-diabetes and microvascular and macrovascular disease in newly diagnosed type 2 diabetes. BMJ Open Diabetes Res Care. (2020) 8:e001061. doi: 10.1136/bmjdrc-2019-001061

89. Chance WW, Rhee C, Yilmaz C, Dane DM, Pruneda ML, Raskin $\mathrm{P}$, et al. Diminished alveolar microvascular reserves in type 2 diabetes reflect systemic microangiopathy. Diabetes Care. (2008) 31:1596-601. doi: 10.2337/dc07-2323

90. Petrie JR, Guzik TJ, Touyz RM. Diabetes, hypertension, and cardiovascular disease: clinical insights and vascular mechanisms. Can J Cardiol. (2018) 34:575-84. doi: 10.1016/j.cjca.2017.12.005

91. Bernard I, Limonta D, Mahal LK, Hobman TC. Endothelium infection and dysregulation by SARS-CoV-2: evidence and caveats in COVID-19. Viruses. (2021) 13:29. doi: 10.3390/v13010029

92. Sims JT, Krishnan V, Chang CY, Engle SM, Casalini G, Rodgers GH, et al. Characterization of the cytokine storm reflects hyperinflammatory endothelial dysfunction in COVID-19. J Allergy Clin Immunol. (2021) 147:107-11. doi: 10.1016/j.jaci.2020.08.031

93. Ciceri F, Beretta L, Scandroglio AM, Colombo S, Landoni G, Ruggeri A, et al. Microvascular COVID-19 lung vessels obstructive thromboinflammatory syndrome (MicroCLOTS): an atypical acute respiratory distress syndrome working hypothesis. Crit Care Resusc. (2020) 22:95-7.

94. Dunn E, Grant P. Type 2 diabetes: an atherothrombotic syndrome. Curr Mol Med. (2005) 5:323-32. doi: 10.2174/1566524053766059

95. McFadyen JD, Stevens H, Peter K. The emerging threat of (micro) thrombosis in COVID-19 and its therapeutic implications. Circ Res. (2020) 127:571-87. doi: 10.1161/CIRCRESAHA.120.317447

96. Fanelli V, Fiorentino M, Cantaluppi V, Gesualdo L, Stallone G, Ronco C, et al. Acute kidney injury in SARS-CoV-2 infected patients. Critical Care. (2020) 24:1-3. doi: 10.1186/s13054-020-02872-Z

97. Richardson S, Hirsch J, Narasimhan M, Crawford J, McGinn T, Davidson $\mathrm{K}$, et al. Presenting characteristics, comorbidities, and outcomes among 5700 patients hospitalized with Covid-19 in the New York City area. JAMA. (2020) 323:2052-9. doi: 10.1001/jama.2020.6775

98. Zou X, Chen K, Zou J, Han P, Hao J, Han Z. Single-cell RNA-seq data analysis on the receptor ACE2 expression reveals the potential risk of different human organs vulnerable to $2019-\mathrm{nCoV}$ infection. Front Med. (2020) 14:185-92. doi: 10.1007/s11684-020-0754-0

99. Kliger AS, Silberzweig J. Mitigating risk of COVID-19 in dialysis facilities. Clin J Am Soc Nephrol. (2020) 15:707-9. doi: 10.2215/CJN.0334 0320

100. Su H, Yang M, Wan C, Yi L-X, Tang F, Zhu H-Y, et al. Renal histopathological analysis of 26 postmortem findings of patients with COVID-19 in China. Kidney Int. (2020) 98:219-27. doi: 10.1016/j.kint.2020.04.003

101. Saraladevi N, Chih-Wei Y, Shang-Jyh H, Bi-Cheng L, Jiang-Hua C, Vivekanand J. The Novel Coronavirus 2019 epidemic and kidneys. Kidney Int. (2020) 97:824-8. doi: 10.1016/j.kint.2020.03.001

102. Li Z, Wu M, Yao J, Guo J, Liao X, Song S, et al. Caution on kidney dysfunctions of COVID-19 patients (2020). doi: 10.2139/ssrn.3559601

103. Shi H, Han X, Jiang N, Cao Y, Alwalid O, Gu J, et al. Radiological findings from 81 patients with COVID-19 pneumonia in Wuhan, China: a descriptive study. Lancet Infect Dis. (2020) 20:425-34. doi: 10.1016/S1473-3099(20)30086-4

104. Guo Y-R, Cao Q-D, Hong Z-S, Tan Y-Y, Chen S-D, Jin H-J, et al. The origin, transmission and clinical therapies on coronavirus disease 2019 
(COVID-19) outbreak-an update on the status. Mil Med Res. (2020) 7:110. doi: 10.1186/s40779-020-00240-0

105. Wang J, Zhu X, Xu Z, Yang G, Mao G, Jia Y, et al. Clinical and CT findings of COVID-19: differences among three age groups. BMC Infect Dis. (2020) 20:1. doi: 10.1186/s12879-020-05154-9

106. Al-Kuraishy HM, Al-Gareeb AI, Alblihed M, Cruz-Martins N, Batiha GE. COVID-19 and risk of acute ischemic stroke and acute lung injury in patients with Type II diabetes mellitus: the anti-inflammatory role of metformin. Front Med. (2021) 8:110 doi: 10.3389/fmed.2021.644295

107. Tang ML, Li YQ, Chen X, Lin H, Jiang ZC, Gu DL, et al. Co-infection with common respiratory pathogens and SARS-CoV-2 in patients with COVID-19 pneumonia and laboratory biochemistry findings: a retrospective cross-sectional study of 78 patients from a single center in China. Med Sci Monit Int Med J Exp Clin Res. (2021) 27:e929783-1. doi: 10.12659/MSM. 929783

108. Marjot T, Webb GJ, Barritt AS, Moon AM, Stamataki Z, Wong VW, et al. COVID-19 and liver disease: mechanistic and clinical perspectives. Nat Rev Gastroenterol Hepatol. (2021) 18:348-64. doi: 10.1038/s41575-021-0 0426-4

109. Eid M, Al-Kaisy M, Regeia W, Jiwa Khan H. The prognostic accuracy of neutrophil-lymphocyte ratio in COVID-19 patients. Front Emerg Med. (2021) 5:e8.

110. Abdel-Moneim A. COVID-19-associated pancreatic dysfunction. Hong Kong Med J. (2021) 27:157-9. doi: 10.12809/hkmj209056

111. Zhang J-j, Dong X, Cao Y-y, Yuan Y-d, Yang Y-b, Yan Y-q, et al. Clinical characteristics of 140 patients infected with SARS-CoV-2 in Wuhan, China. Allergy. (2020) 75:1730-41. doi: 10.1111/all.14238

112. Gupta R, Ghosh A, Singh AK, Misra A. Clinical considerations for patients with diabetes in times of COVID-19 epidemic. Diabetes Metab Syndrome. (2020) 14:211. doi: 10.1016/j.dsx.2020.03.002

113. Whyte CS, Morrow GB, Mitchell JL, Chowdary P, Mutch NJ. Fibrinolytic abnormalities in acute respiratory distress syndrome (ARDS) and versatility of thrombolytic drugs to treat COVID-19. J Thromb Haemost. (2020) 18:1548-55. doi: 10.1111/jth.14872

114. Philips BJ, Meguer J-X, Redman J, Baker EH. Factors determining the appearance of glucose in upper and lower respiratory tract secretions. Intens Care Med. (2003) 29:2204-10. doi: 10.1007/s00134-003-1961-2

115. Al-kuraishy H, Al-Gareeb AI, Guerreiro SG, Cruz-Martins N, Batiha GE. COVID-19 in relation to hyperglycemia and diabetes mellitus. Front Cardiovasc Med. (2021) 8:335. doi: 10.3389/fcvm.2021.644095

116. Kaiser UB, Mirmira RG, Stewart PM. Our Response to COVID-19 as Endocrinologists and Diabetologists. Washington, DC: Oxford University Press US (2020).

117. Baldeweg S, Ball S, Brooke A, Gleeson H, Levy M, Prentice M, et al. SOCIETY FOR ENDOCRINOLOGY CLINICAL GUIDANCE: inpatient management of cranial diabetes insipidus. Endocr Connect. (2018) 7:G8G11. doi: 10.1530/EC-18-0154

118. Solerte SB, D’Addio F, Trevisan R, Lovati E, Rossi A, Pastore I, et al. Sitagliptin treatment at the time of hospitalization was associated with reduced mortality in patients with type 2 diabetes and COVID-19: a multicenter, case-control, retrospective, observational study. Diabetes Care. (2020) 43:2999-3006. doi: 10.2337/dc20-1521

119. Peng Y, Meng K, Guan H, Leng L, Zhu R, Wang B, et al. Clinical characteristics and outcomes of 112 cardiovascular disease patients infected by 2019-nCoV. Zhonghua Xin Xue Guan Bing Za Zhi. (2020) 48:4505. doi: 10.3760/cma.j.cn112148-20200220-00105

120. Wang T, Du Z, Zhu F, Cao Z, An Y, Gao Y, et al. Comorbidities and multi-organ injuries in the treatment of COVID-19. Lancet. (2020) 395:e52. doi: 10.1016/S0140-6736(20)30558-4

121. Yan Y, Yang Y, Wang F. Clinical characteristics and outcomes of severe COVID-19 patients with diabetes. BMJ Open Diabetes Res Care. (2020) 8:1-9. doi: 10.1136/bmjdrc-2020-001343

122. Singh AK, Singh R. Does poor glucose control increase the severity and mortality in patients with diabetes and COVID-19? Diabetes Metab Syndrome Clin Res Rev. (2020) 14:725-7. doi: 10.1016/j.dsx.2020. 05.037

123. Rekedal LR, Massarotti E, Garg R, Bhatia R, Gleeson T, Lu B, et al. Changes in glycosylated hemoglobin after initiation of hydroxychloroquine or methotrexate treatment in diabetes patients with rheumatic diseases. Arthritis Rheum. (2010) 62:3569-73. doi: 10.1002/art.27703

124. Gerstein HC, Thorpe KE, Taylor DW, Haynes RB. The effectiveness of hydroxychloroquine in patients with type 2 diabetes mellitus who are refractory to sulfonylureas-a randomized trial. Diabetes Res Clin Pract. (2002) 55:209-19. doi: 10.1016/S0168-8227(01)00325-4

125. Kumar V, Singh M, Singh AP, Pandey MS, Kumar S, Kumar S. Efficacy and safety of hydroxychloroquine when added to stable insulin therapy in combination with metformin and glimepiride in patients with type 2 diabetes compare to sitagliptin. Int $J$ Basic Clin Pharmacol. (2018) 7:1959-64. doi: 10.18203/2319-2003.ijbcp2018 3930

126. Micallef J, Soeiro T, Annie-Pierre JB. Non-steroidal anti-inflammatory drugs, pharmacology, and COVID-19 infection. Therapies. (2020) 75:35562. doi: $10.1016 /$ j.therap. 2020.05 .003

127. Prescott HC, Rice TW. Corticosteroids in COVID-19 ARDS: evidence and hope during the pandemic. JAMA. (2020) 324:1292-5. doi: 10.1001/jama.2020.16747

128. Xuan X, Gao F, Ma X, Huang C, Wang Y, Deng $H$, et al. Activation of ACE2/angiotensin (1-7) attenuates pancreatic $\beta$ cell dedifferentiation in a high-fat-diet mouse model. Metabolism. (2018) 81:83-96. doi: 10.1016/j.metabol.2017.12.003

129. Henry C, Zaizafoun M, Stock E, Ghamande S, Arroliga AC, White HD, editors. Impact of angiotensin-converting enzyme inhibitors and statins on viral pneumonia. In: Baylor University Medical Center Proceedings. Dallas: Taylor \& Francis (2018).

130. Magro P, Zanella I, Pescarolo M, Castelli F, Quiros-Roldan E. Lopinavir/ritonavir: repurposing an old drug for HIV infection in COVID-19 treatment. Biomed J. (2020) 44:43-53. doi: 10.1016/j.bj.2020. 11.005

131. Gullestad L, Aukrust P, Ueland T, Espevik T, Yee G, Vagelos R, et al. Effect of high-versus low-dose angiotensin converting enzyme inhibition on cytokine levels in chronic heart failure. J Am Coll Cardiol. (1999) 34:20617. doi: 10.1016/S0735-1097(99)00495-7

132. Mortensen E, Pugh M, Copeland L, Restrepo M, Cornell J, Anzueto A, et al. Impact of statins and angiotensin-converting enzyme inhibitors on mortality of subjects hospitalised with pneumonia. Eur Respir J. (2008) 31:611-7. doi: 10.1183/09031936.00162006

133. Sardu C, Gambardella J, Morelli MB, Wang X, Marfella R, Santulli G. Is COVID-19 an endothelial disease? Clin Basic Evid. (2020) 9:1417. doi: $10.3390 / \mathrm{jcm} 9051417$

134. Ciccarelli M, Santulli G, Campanile A, Galasso G, Cervero P, Altobelli G, et al. Endothelial $\alpha 1$-adrenoceptors regulate neo-angiogenesis. $\mathrm{Br} J$ Pharmacol. (2008) 153:936-46. doi: 10.1038/sj.bjp.0707637

135. Amer MS, McKeown L, Tumova S, Liu R, Seymour VA, Wilson LA, et al. Inhibition of endothelial cell $\mathrm{Ca}^{2+}$ entry and transient receptor potential channels by Sigma-1 receptor ligands. Br J Pharmacol. (2013) 168:144555. doi: 10.1111/bph.12041

136. Shishavan MH, Henning RH, Van Buiten A, Goris M, Deelman LE, Buikema H. Metformin improves endothelial function and reduces blood pressure in diabetic spontaneously hypertensive rats independent from glycemia control: comparison to vildagliptin. Sci Rep. (2017) 7:112. doi: 10.1038/s41598-017-11430-7

137. Bolz S-S, Pohl U. Indomethacin enhances endothelial NO release-evidence for a role of PGI2 in the autocrine control of calcium-dependent autacoid production. Cardiovasc Res. (1997) 36:437-44. doi: 10.1016/S0008-6363(97)00197-1

138. Sfikakis P, Papamichael C, Stamatelopoulos K, Tousoulis D, Fragiadaki K, Katsichti $\mathrm{P}$, et al. Improvement of vascular endothelial function using the oral endothelin receptor antagonist bosentan in patients with systemic sclerosis. Arthritis Rheum. (2007) 56:1985-93. doi: 10.1002/art.22634

139. Lee E, Pavy M, Young N, Freeman C, Lobigs M. Antiviral effect of the heparan sulfate mimetic, PI-88, against dengue and encephalitic flaviviruses. Antiviral Res. (2006) 69:31-8. doi: 10.1016/j.antiviral.20 05.08.006

140. Gurwitz D. Angiotensin receptor blockers as tentative SARS-CoV2 therapeutics. Drug Dev Res. (2020) 81:537-40. doi: 10.1002/ddr. 21656 
141. Li H, Zhou Y, Zhang M, Wang H, Zhao Q, Liu J. Updated approaches against SARS-CoV-2. Antimicrob Agents Chemother. (2020) 64:e00483-20. doi: 10.1128/AAC.00 483-20

Conflict of Interest: The authors declare that the research was conducted in the absence of any commercial or financial relationships that could be construed as a potential conflict of interest.
Copyright ๑ 2021 Magdy Beshbishy, Oti, Hussein, Rehan, Adeyemi, Rivero-Perez, Zaragoza-Bastida, Shah, Abouelezz, Hetta, Cruz-Martins and Batiha. This is an open-access article distributed under the terms of the Creative Commons Attribution License (CC BY). The use, distribution or reproduction in other forums is permitted, provided the original author(s) and the copyright owner(s) are credited and that the original publication in this journal is cited, in accordance with accepted academic practice. No use, distribution or reproduction is permitted which does not comply with these terms. 